\title{
Hydrogenation of tetralin over Pt catalysts supported on sulfated zirconia and amorphous silica alumina
}

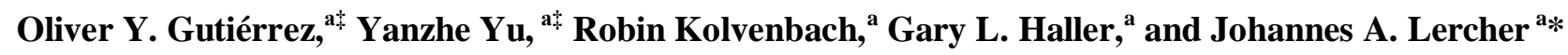 \\ Received (in $X X X, X X X)$ Xth $X X X X X X X X X 20 X X$, Accepted Xth $X X X X X X X X X 20 X X$ \\ ${ }_{5}$ DOI: 10.1039/b000000x
}

Pt supported on sulfated zirconia (SZ) and amorphous silica alumina (ASA) was explored for the hydrogenation of tetralin. Pt/ASA had a higher concentration and strength of acid sites than the SZsupported counterpart, for which the acid site concentration of the carrier decreases after catalyst synthesis due to sulfur elimination. The strong acidity of Pt/ASA caused higher deactivation due to coke 10 deposition, while Pt/SZ was comparatively stable. Pt/ASA also exhibited higher porosity and Pt dispersion than Pt/SZ. The adsorption of CO, the XANES analysis and gravimetric sorption of benzene showed that the Pt particles on SZ were strongly electron deficient, a feature that has been speculated to be associated to the electron withdrawing effect of sulfate groups. For tetralin hydrogenation, Pt/SZ was more active than Pt/ASA above $423 \mathrm{~K}$ while the opposite was observed at $413 \mathrm{~K}$. The apparent activation

15 energies were 98 and $45 \mathrm{~kJ} / \mathrm{mol}$ on Pt/SZ and Pt/ASA, respectively. Pt/ASA was more active than Pt/SZ in the presence of quinoline, while $\mathrm{Pt} / \mathrm{SZ}$ retains the highest activity in the presence of dibenzothiophene (with or without quinoline). The lower apparent activation energy on Pt/ASA in the absence of quinoline or dibenzothiophene and its higher activity in the presence of quinoline were attributed to its strong Brønsted acidity, promoting the hydrogenation at the perimeter of Pt particles. The higher sulfur 20 resistance of $\mathrm{Pt} / \mathrm{SZ}$ was attributed to the electron deficiency of the supported Pt particles. In this respect, surface sulfate anions induce stronger electron deficiency in supported Pt than the acidity of the support.

\section{Introduction}

In order to achieve the high-quality diesel fuel required to meet present day environmental regulations, a two-stage process has ${ }_{25}$ been widely proposed. ${ }^{1,2}$ In the first stage, metal sulfides, such as $\mathrm{Co}(\mathrm{Ni})-\mathrm{MoS}_{2}$, are used to minimize the content of heteroatoms, whereas in the second stage deep hydrogenation of aromatics is conducted on supported noble metals. These noble metal-based catalysts exhibit high hydrogenation activity at relatively mild 30 reaction conditions, but the rates observed with these catalysts is dramatically reduced by competitive adsorption of molecules containing heteroatoms and the associated partial sulfidation of the metal particles. ${ }^{3}$ These negative effects can be reduced by using acidic supports, which is attributed to electronic transfer 35 from noble metal particles towards the support. ${ }^{3-7}$ Additionally, Brønsted acid sites at the perimeter of the metal particles may facilitate the hydrogenation of aromatics. ${ }^{6-9}$

Sulfated zirconia (SZ) is an acidic solid suitable for catalyzing numerous reactions at remarkably low temperatures. ${ }^{10}$ Few

40 papers have addressed the hydrogenation activity of Pt supported on SZ, ${ }^{11,12}$ probably due to the acid-catalyzed reactions occurring on the latter, which makes it difficult to exclusively study the hydrogenation properties of supported Pt. It is established that SZ-supported Pt particles are electron deficient due to their 45 interaction with sulfur species of the support. ${ }^{13-16}$, Thus, we expected that supported Pt exhibits outstanding hydrogenation activity even in the presence of sulfur and nitrogen containing molecules. In the present work, we study the hydrogenation activity and poison resistance of $\mathrm{Pt}$ particles supported on 50 sulfated zirconia using model compounds. The properties and performance of $\mathrm{Pt} / \mathrm{SZ}$ are compared to $\mathrm{Pt}$ supported on amorphous silica alumina (ASA), whose hydrogenation performance has been studied in more detail. ${ }^{7-9}$

\section{Experimental}

\section{${ }_{55}$ Catalyst preparation}

Sulfated zirconia (MEL Cat, XZO 1249) and ASA (Sasol Germany, SIRAL 30, $\mathrm{SiO}_{2} / \mathrm{Al}_{2} \mathrm{O}_{3}$ weight ratio of 70/30) were used as supports. SZ and ASA were thermally treated in air at $873 \mathrm{~K}$ for $3 \mathrm{~h}$, and $823 \mathrm{~K}$ for $4 \mathrm{~h}$, respectively. After those 60 treatments, both materials were impregnated with aqueous solutions of $\mathrm{Pt}\left(\mathrm{NH}_{3}\right)_{4}\left(\mathrm{NO}_{3}\right)_{2}$ (Aldrich, 99.995\%), dried and treated consecutively in flowing air at $673 \mathrm{~K}$ for $2 \mathrm{~h}$ and in hydrogen at $623 \mathrm{~K}$ for $4 \mathrm{~h}$. The nominal Pt loading in both catalysts was 0.8 wt.\%. The Pt catalysts supported on sulfated ${ }_{65}$ zirconia and ASA are denoted in the following as Pt/SZ and Pt/ASA, respectively. 


\begin{tabular}{|c|c|c|c|c|c|c|c|c|}
\hline \multirow{3}{*}{$\begin{array}{l}\text { Support or } \\
\text { catalyst }\end{array}$} & \multirow{3}{*}{$\begin{array}{c}\text { BET Surface } \\
\text { area } \\
\left(\mathrm{m}^{2} \mathrm{~g}^{-1}\right)\end{array}$} & \multirow{3}{*}{$\begin{array}{l}\text { Pt content } \\
\text { (wt.\%) }\end{array}$} & \multirow{3}{*}{$\begin{array}{l}\text { Pt particle } \\
\text { size }^{1} \\
(\mathrm{~nm})\end{array}$} & \multirow{3}{*}{$\begin{array}{l}\text { Pt particle } \\
\text { size }^{2} \\
(\mathrm{~nm})\end{array}$} & \multicolumn{4}{|c|}{$\begin{array}{c}\text { Acid site } \\
\text { concentration } \\
\left(\mu \mathrm{mol} \cdot \mathrm{g}^{-1}\right)\end{array}$} \\
\hline & & & & & \multicolumn{2}{|c|}{ BAS } & \multicolumn{2}{|c|}{ LAS } \\
\hline & & & & & Total & Strong & Total & Strong \\
\hline SZ & 165 & - & - & - & 139 & 86 & 256 & 135 \\
\hline $\mathrm{Pt} / \mathrm{SZ}$ & 165 & 0.81 & 2.3 & 1.7 & 26 & 8 & 343 & 153 \\
\hline ASA & 481 & - & - & - & 56 & 29 & 526 & 246 \\
\hline Pt/ASA & 423 & 0.793 & 1.1 & 1.3 & 41 & 25 & 387 & 234 \\
\hline
\end{tabular}
pressure of 0.5 mbar.

${ }^{1}$ Mean metal particle sizes calculated as $\mathrm{C} / \mathrm{D}$, where $\mathrm{C}$ is 1.13 for $\mathrm{Pt}$ and $\mathrm{D}$ is the dispersion calculated from $\mathrm{H}_{2}$ chemisorption. ${ }^{21}$

${ }^{2}$ Metal particle sizes calculated from TEM measurements.

\section{${ }_{5}$ Catalyst characterization}

The concentration of $\mathrm{Pt}$ in the catalysts was determined by atomic absorption spectroscopy (AAS) using a UNICAM 939 spectrometer. Carbon and sulfur contents of fresh and spent catalysts were determined using a Vario EL analyzer 10 (ELEMENTAR). The texture of supports and catalysts were determined from $\mathrm{N}_{2}$ adsorption measurements carried out at $77 \mathrm{~K}$ using a PMI automated BET sorptometer. Prior to the measurements, all materials were outgassed at $523 \mathrm{~K}$ for $20 \mathrm{~h}$. Specific surface areas and porosities were calculated applying $15 \mathrm{BET}$ and $\mathrm{BJH}$ theories, respectively. The dispersion of $\mathrm{Pt}$ was measured by $\mathrm{H}_{2}$ chemisorption at $298 \mathrm{~K}$ after activation in vacuum at $588 \mathrm{~K}$ for $1 \mathrm{~h}$. Two adsorption isotherms were measured from 1 to $40 \mathrm{kPa}$, that is, before and after outgassing at 298 for $1 \mathrm{~h}$. The metal dispersion was estimated from the 20 concentration of chemisorbed hydrogen, calculated by subtracting the second isotherm from the first one. The average particle sizes of Pt particles in the catalysts were measured by TEM. Samples were ground, suspended in ethanol and ultrasonically dispersed and the dispersion drops were applied on a copper-carbon grid. 25 Measurements were carried out on a transmission electron microscope device JEOL JEM-2011 with an accelerating voltage of $120 \mathrm{keV}$.

Infrared spectra of adsorbed pyridine and $\mathrm{CO}$ were measured to characterize the acidity of the materials and properties of the 30 supported metal, respectively. The adsorption of pyridine was monitored with a Perkin Elmer 2000 spectrometer operating at a resolution of $4 \mathrm{~cm}^{-1}$. Prior to the pyridine sorption experiments, the catalyst samples were activated at $10^{-6}$ mbar and $723 \mathrm{~K}$ for 1 $\mathrm{h}$. The activated samples were exposed to pyridine $\left(\mathrm{p}_{(\mathrm{Py})}=10^{-1}\right.$ $35 \mathrm{mbar}$ ) at $423 \mathrm{~K}$ for $0.5 \mathrm{~h}$ and after evacuation at $423 \mathrm{~K}$ for $1 \mathrm{~h}$ the IR spectra were recorded. These spectra corresponded to pyridine adsorbed on all acid sites. Afterwards, the samples were heated at $723 \mathrm{~K}$ in vacuum for $1 \mathrm{~h}$ and another series of spectra was collected corresponding to pyridine adsorbed on strong acid sites.

40 The concentration of weak acid sites was determined by subtracting both series of spectra. The concentrations of Lewis (LAS) and Brønsted (BAS) acid sites were quantified using the

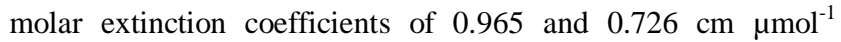
respectively. ${ }^{17}$ The adsorption of $\mathrm{CO}$ was measured using a ${ }_{45}$ Bruker VERTEX 70 with a resolution of $2 \mathrm{~cm}^{-1}$. The catalysts were activated in $\mathrm{H}_{2}$ for $1 \mathrm{~h}$ followed by evacuation $\left(\mathrm{p}=10^{-6}\right.$ mbar) for $1 \mathrm{~h}$ at $623 \mathrm{~K}$. Then, the catalysts were cooled to $313 \mathrm{~K}$,
60 flow $\left(10 \mathrm{ml} \cdot \mathrm{min}^{-1}\right)$ with a heating rate of $3 \mathrm{~K} \cdot \mathrm{min}^{-1}$. A mass spectrometer (Balzers QME 200) was used for monitoring the evolved gases.

X-ray absorption spectra were collected at the beamlines X1 at HASYLAB, DESY, Hamburg, Germany. The storage ring was 65 operated at $4.5 \mathrm{GeV}$ at an average current of $100 \mathrm{~mA}$. The $\mathrm{Si}$ (311) double crystal monochromator was detuned to $60 \%$ of the maximum intensity to minimize the intensity of higher harmonics in the X-ray beam. Self-supporting wafers of the catalysts were first reduced with $\mathrm{H}_{2}$ in situ at $623 \mathrm{~K}$ for $1 \mathrm{~h}$ and then flushed 70 with $\mathrm{He}$ at $623 \mathrm{~K}$ for $0.5 \mathrm{~h}$ to remove adsorbed $\mathrm{H}_{2}$. The $\mathrm{X}$-ray absorption spectra were collected at the $\mathrm{Pt}_{\mathrm{III}}$ edge $(11564 \mathrm{eV})$ at $77 \mathrm{~K}$. The position of the edge was calibrated using the spectra of a simultaneously measured $\mathrm{Pt}$ foil. The scattering contributions in the pre- and post-edge of the background were removed from the 75 X-ray absorption using a third-order polynomial function and afterwards all spectra were normalized to the average post-edge height of one in the region of $11564 \mathrm{eV}$ above the edge. The XANDA programs were used for analyzing the data. ${ }^{18}$

In order to explore the adsorption of aromatics on the catalysts, 80 gravimetric sorption isotherms of benzene on $\mathrm{Pt} / \mathrm{ASA}$ and $\mathrm{Pt} / \mathrm{SZ}$ were measured in a Seteram TG-DSC 111 thermoanalyzer connected to a high vacuum system. Samples of the reduced materials (approximately $20 \mathrm{mg}$ ) were placed in a quartz sample holder and activated at $523 \mathrm{~K}$ for $1 \mathrm{~h}$ under vacuum $\left(\mathrm{p}<10^{-4} \mathrm{mbar}\right)$ 85 with an incremental heating rate of $10 \mathrm{~K} \cdot \mathrm{min}^{-1}$. The equilibration with the sorbate was performed in small pressure steps from $3 \cdot 10^{-}$

${ }^{2}$ to 1.2 mbar, whereas the mass increase and the thermal flux were measured. The overall heat of adsorption was obtained by integration of the observed heat flux signal. In order to obtain the 90 maximum uptake, and enthalpy and entropy of adsorption on the metal site phase and the support, the data was analyzed according to the dual site Langmuir formalism shown in Eq. $i$, where $n(p)$ is the adsorbed amount, $\mathrm{K}_{\mathrm{i}}$ is the adsorption equilibrium constant, $\mathrm{p}$ is the pressure of benzene and $n_{\max , i}$ is the maximum coverage on 95 the metal phase or the support (denoted by i). In order to reduce the number of parameters, the enthalpy $(\Delta \mathrm{H})$ and entropy $(\Delta \mathrm{S})$ of adsorption were used as parameters for the fitting procedure according to Eq. ii. Nonlinear parameter fitting was carried out using a CMA evolutional strategy implemented in MATLAB. ${ }^{19}$

100

$$
\begin{aligned}
& n(p)=\sum \frac{K_{i} * p * n_{\max , i}}{1+K_{i} * p} \\
& K_{i}=\exp \left(-\frac{\Delta H_{a d s, i}}{R T}\right) * \exp \left(\frac{\Delta S_{a d s, i}}{R}\right)
\end{aligned}
$$




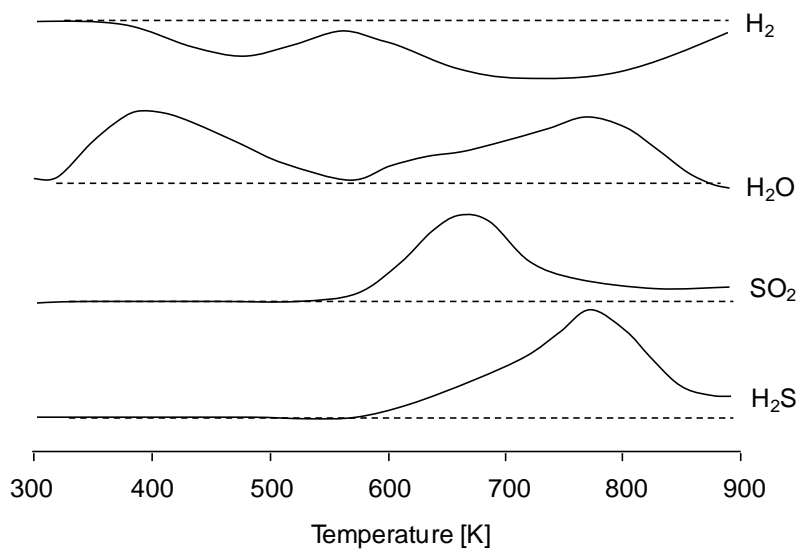

Fig. 1 Temperature programmed reduction profiles of $\mathrm{H}_{2} \mathrm{O}, \mathrm{SO}_{2}$ and $\mathrm{H}_{2} \mathrm{~S}$ of un-reduced $\mathrm{Pt} / \mathrm{SZ}$.

\section{Activity test}

5 Hydrogenation of tetralin in the absence and presence of quinoline and dibenzothiophene (DBT) was used as a model reaction to investigate the catalytic activities of $\mathrm{Pt} / \mathrm{SZ}$ and Pt/ASA. The reactions were carried out in a set of 4 parallel trickle-bed reactors in continuous down-flow mode. ${ }^{20}$ The

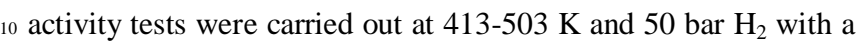
weight hourly space velocity (WHSV) of $1500 \mathrm{~h}^{-1}$ for poison-free feed (i.e., without quinoline or dibenzothiophene), of $300 \mathrm{~h}^{-1}$ for feed containing quinoline, $60 \mathrm{~h}^{-1}$ for DBT-containing feed, and 21 $\mathrm{h}^{-1}$ for feed containing quinoline and DBT (WHSV is defined as 15 the weight of feed per hour per unit weight of catalyst). The change in WHSV was achieved by varying the amount of catalyst and the flow rate keeping a constant molar ratio of $\mathrm{H}_{2}$ to tetralin of 75 . The poison-free feed consisted of $5 \mathrm{wt} . \%$ tetralin, and 5 wt.\% hexadecane as GC standard in tetradecane. In catalytic 20 experiments in the presence of DBT or quinoline in separate tests, 0.058 wt.\% DBT and 0.37 wt.\% quinoline was used, whereas in the experiments with both compounds 0.019 and 0.058 wt.\% quinoline and DBT, respectively, were used. Continuous deactivation was observed in all reactions in the first $20 \mathrm{~h}$ time on

25 stream (TOS) of the reaction. Thus, all catalytic activities here reported were collected at steady state after $24 \mathrm{~h}$ of time TOS.

\section{Results and discussion}

\section{Physicochemical properties of supports and catalysts}

The physicochemical properties of supports and catalysts are 30 summarized in Table 1. Compared to the respective supports, the specific surface area of $\mathrm{Pt} / \mathrm{SZ}$ did not change, that of Pt/ASA slightly decreased. The H/Pt ratios were 0.50 and 1.07 for $\mathrm{Pt} / \mathrm{SZ}$ and Pt/ASA, respectively. The corresponding average Pt particle sizes have been estimated to be $2.3 \mathrm{~nm}$ for $\mathrm{Pt} / \mathrm{SZ}$ and $1.1 \mathrm{~nm}$ for ${ }_{35} \mathrm{Pt} / \mathrm{ASA}^{21}$ The average particle size derived from TEM measurements was $1.3 \mathrm{~nm}$ for $\mathrm{Pt} / \mathrm{ASA}$, i.e., larger than that determined from $\mathrm{H}_{2}$-chemisorption. Most probably, the smaller metal particles escaped detection during analysis of the TEM images causing the overestimation of the average particle size. In
40 contrast, for Pt/SZ, the Pt particle size derived from TEM was 1.7 $\mathrm{nm}$, i.e., smaller than that determined from chemisorbed $\mathrm{H}_{2}$. This is attributed to partial coverage of $\mathrm{Pt}$ particles by sulfur released from the carrier and reduced during the synthesis steps (vide infra), which blocked to some extent the adsorption of $\mathrm{H}_{2}$. The 45 dispersion of Pt/ASA was higher than that of Pt/SZ likely due to the higher specific surface area and concentration of Lewis acid sites on the former support, which are likely anchoring sites for $\mathrm{Pt}$ particles. $^{22}$

The Brønsted and Lewis acid site concentrations on ASA ${ }_{50}$ decreased during the preparation of the Pt catalyst. For Pt/SZ, the concentration of Brønsted acid sites decreased drastically, whereas the concentration of Lewis acid sites increased after $\mathrm{Pt}$ loading. Both observations are attributed to dehydration and decomposition of sulfate groups during the thermal treatments. ${ }_{55}$ Reactions (1) and (2) have been proposed for the creation of Lewis acid sites. ${ }^{23,24}$ Accordingly, the sulfur content of the assynthesized $\mathrm{Pt} / \mathrm{SZ}$ was lower than that of the pure support $(1.50$ and $2.14 \mathrm{wt}$. $\%$, respectively). It is important to mention that the concentration of Brønsted sites is not a simple function of the 60 sulfur concentration as it seems that isolated sulfate species do not produce $\mathrm{Br} \varnothing n s t e d$ acidity. ${ }^{25,26}$

$\mathrm{HSO}_{4}^{-}+\mathrm{Zr}-\mathrm{OH} \rightarrow \mathrm{SO}_{4}{ }^{2-}+\mathrm{H}_{2} \mathrm{O}$
$2 \mathrm{Zr}^{4+}+\mathrm{SO}_{4}{ }^{2-} \rightarrow 2 \mathrm{Zr}^{3+}+\mathrm{SO}_{2}+\mathrm{O}_{2}$

The evolution profiles of $\mathrm{H}_{2} \mathrm{O}, \mathrm{SO}_{2}$ and $\mathrm{H}_{2} \mathrm{~S}$ recorded during ${ }_{65}$ TPR of not-reduced Pt/SZ are shown in Figure 1. The units in the Figure are arbitrary, however, the release-uptake profiles allow a qualitative description of the phenomena involved in TPR. Hydrogen exhibits two consumption signals in the ranges of 370$570 \mathrm{~K}$, and $570-900 \mathrm{~K}$. The water evolution signal below $600 \mathrm{~K}$ 70 is attributed to the desorption of physisorbed water (maximum at $380 \mathrm{~K}$ ) and the reduction of $\mathrm{Pt}$ oxide species (in the range of low temperature $\mathrm{H}_{2}$-consumtpion ${ }^{27,28}$ ) according to reaction (3). Water desorption above $600 \mathrm{~K}$ is coupled with the release of $\mathrm{SO}_{2}$ and $\mathrm{H}_{2} \mathrm{~S}$, with maxima at 670 and $770 \mathrm{~K}$, respectively. The 75 release of these two compounds was attributed to elimination of surface sulfate groups as $\mathrm{SO}_{2}$ at low temperature and $\mathrm{H}_{2} \mathrm{~S}$ at high temperature due to Pt-catalyzed $\mathrm{SO}_{2}$ reduction ${ }^{29}$ as shown in Reaction (4). Alternatively, the two different decomposition mechanisms presented in Reactions (5) and (6) have also been 80 proposed. ${ }^{30}$ These results indicate that surface sulfate groups are eliminated from $\mathrm{Pt} / \mathrm{SZ}$ during the synthesis and, therefore, the Brønsted acidity decreases because the concentration of Brønsted acid sites depends on the concentration of surface sulfates. ${ }^{31}$ Conversely, the concentration of Lewis acid sites increased with 85 the thermal treatment due to the conversion of Brønsted into Lewis acid sites on the removal of chemisorbed water and $\mathrm{SO}_{4}{ }^{2-}$ 10

$$
\begin{aligned}
& \mathrm{PtO}_{\mathrm{x}}+\mathrm{xH}_{2} \rightarrow \mathrm{Pt}+\mathrm{xH}_{2} \mathrm{O} \\
& \mathrm{SO}_{2}+3 \mathrm{H}_{2} \rightarrow \mathrm{H}_{2} \mathrm{~S}+2 \mathrm{H}_{2} \mathrm{O} \\
& { }_{90} \mathrm{Zr}-\mathrm{SO}_{4}-\mathrm{Zr}+4 \mathrm{H}_{2} \rightarrow \mathrm{Zr}-\mathrm{O}-\mathrm{Zr}+\mathrm{H}_{2} \mathrm{~S}+3 \mathrm{H}_{2} \mathrm{O} \\
& \mathrm{Zr}-\mathrm{SO}_{4}-\mathrm{Zr}+\mathrm{H}_{2} \rightarrow \mathrm{Zr}-\mathrm{O}-\mathrm{Zr}+\mathrm{SO}_{2}+\mathrm{H}_{2} \mathrm{O}
\end{aligned}
$$




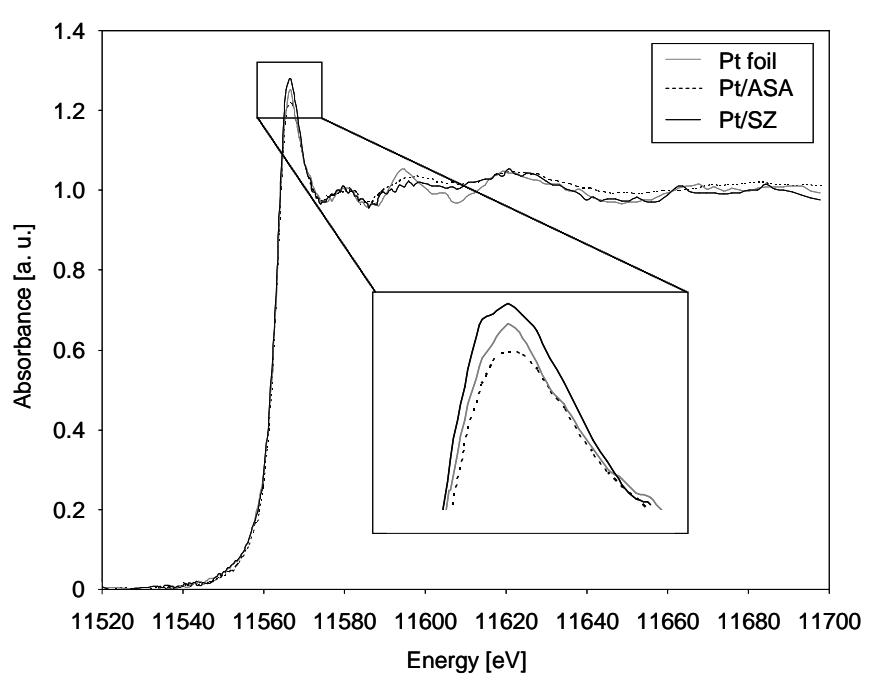

Fig. 2 Normalized XANES at the Pt LIII edge in He at $623 \mathrm{~K}$ of Pt foil and $\mathrm{Pt} / \mathrm{ASA}, \mathrm{Pt} / \mathrm{SZ}$ catalysts after in situ reduction in $\mathrm{H}_{2}$ at $623 \mathrm{~K}$.

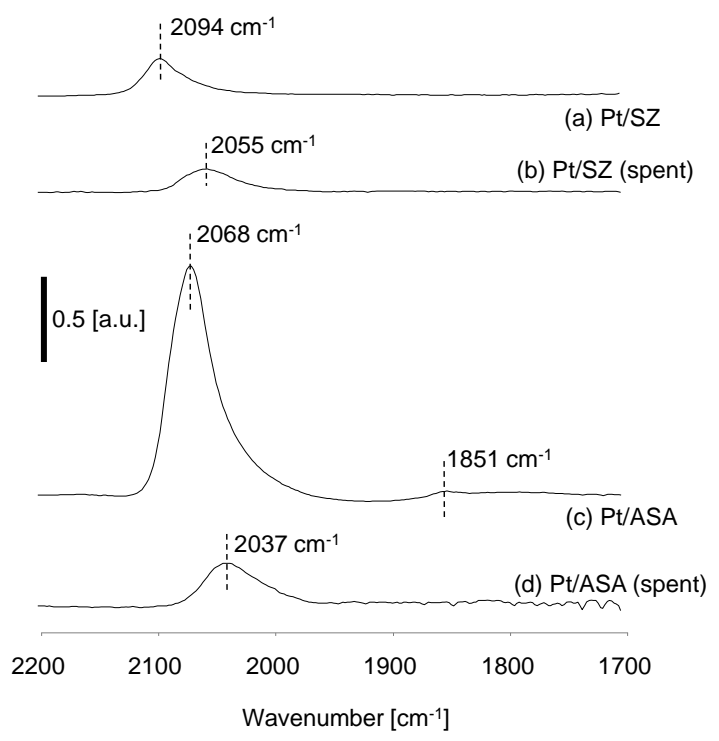

Fig. 3 IR spectra of CO adsorbed on (a) Pt/SZ, (b) spent Pt/SZ, (c) $\mathrm{Pt} / \mathrm{ASA}$ and (d) spent Pt/ASA catalysts at $\mathrm{T}=40^{\circ} \mathrm{C}, \mathrm{p}(\mathrm{CO})=5 \cdot 10-1$

5 mbar and evacuation for $15 \mathrm{~min}$. Spent catalysts (b) and (d) were Pt/SZ and Pt/ASA after TOS of $24 \mathrm{~h}$ in tetralin hydrogenation reaction $(\mathrm{p}=50$ bar, $\mathrm{T}=453 \mathrm{~K}$, in poison-free feed).

\section{Characterization of the Pt particles}

The electronic states of $\mathrm{Pt}$ particles in the catalysts were 10 compared to that in bulk Pt by X-ray absorption spectroscopy (Figure 2). The integrated intensities of the XANES at the Pt $\mathrm{L}_{\mathrm{III}}$ edge were obtained by calculating the area enclosed between the XANES and a sigmoidal function fitting the edge. ${ }^{32}$ The intensities were 1.52, 0.99, and 1.27 a.u. for Pt/SZ, Pt/ASA and $15 \mathrm{Pt}$ foil, respectively. It is known that the XANES intensity is proportional to the hole density at the $5 d_{5 / 2}$ and $5 d_{3 / 2}$ states of Pt. Therefore, the differences in the white line intensities in Fig. 2 and the integrated XANES area indicate a lower electron density of Pt on sulfated zirconia compared to bulk and ASA supported $20 \mathrm{Pt}$.

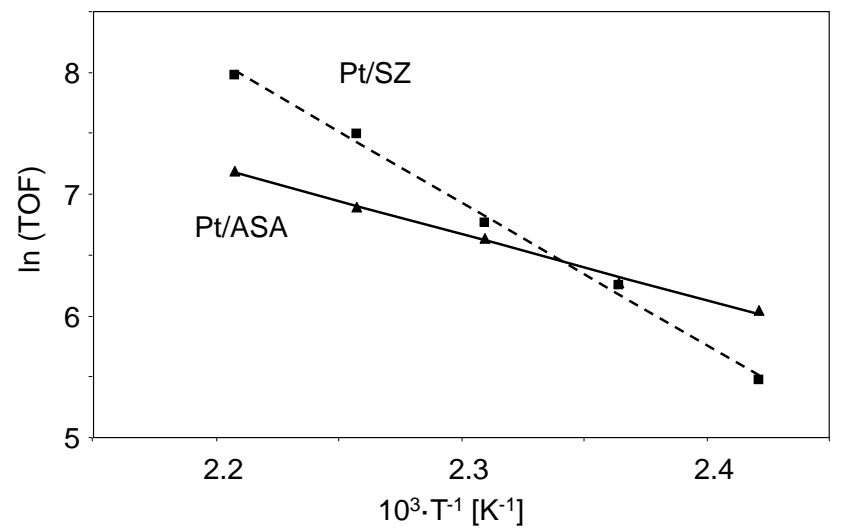

Fig. 4 Arrhenius plots for the hydrogenation of tetralin over Pt/SZ and $\mathrm{Pt} / \mathrm{ASA}$ at 50 bar $_{2}$ and $413-453 \mathrm{~K}$.

The Pt particles of $\mathrm{Pt} / \mathrm{SZ}$ and $\mathrm{Pt} / \mathrm{ASA}$ were further characterized by IR spectra of adsorbed CO. In Fig. 3, spectra (a) 25 and (c) correspond to $\mathrm{CO}$ adsorbed on as-reduced Pt/SZ and Pt/ASA. Bands observed at 2094 and $2068 \mathrm{~cm}^{-1}$ for Pt/SZ and $\mathrm{Pt} / \mathrm{ASA}$, respectively, are attributed to CO linearly adsorbed on Pt. ${ }^{33}$ Additionally, a low-intensity band at $1851 \mathrm{~cm}^{-1}$, observed for Pt/ASA, was assigned to bridging CO adsorbed on $\mathrm{Pt}^{34}$

30 The higher wavenumber of $\mathrm{CO}$ adsorbed on $\mathrm{Pt} / \mathrm{SZ}$ than on $\mathrm{Pt} / \mathrm{ASA}$ indicated weaker $\mathrm{CO}$ adsorption likely due to relatively low electron density of $\mathrm{Pt}$ in the former catalyst. ${ }^{34}$ Additionally, the normalized area of linearly adsorbed $\mathrm{CO}$ on Pt/ASA was significantly higher than that of $\mathrm{Pt} / \mathrm{SZ}$, which is attributed to the 35 higher dispersion of Pt in Pt/ASA and to the partial coverage of the metal particles on SZ by sulfur removed from the carrier during the synthesis.

\section{Hydrogenation of tetralin on $\mathrm{Pt} / \mathrm{SZ}$ and $\mathrm{Pt} / \mathrm{ASA}$ in the} absence of quinoline and DBT

40 The hydrogenation of tetralin was carried out from 413 to $503 \mathrm{~K}$. In this temperature range only hydrogenated products were observed. Figure 4 shows the temperature dependence of turnover frequency (TOF) of the hydrogenation of tetralin on Pt/SZ and Pt/ASA. The former is more active above $423 \mathrm{~K}$ than the latter. ${ }_{45}$ At $423 \mathrm{~K}$ both catalysts have the same activity and, at the temperatures at which the reaction was measured, only at $413 \mathrm{~K}$ $\mathrm{Pt} / \mathrm{ASA}$ is more active than $\mathrm{Pt} / \mathrm{SZ}$. The apparent activation energies $\left(\mathrm{E}_{\mathrm{a}(\exp )}\right)$ were 98 and $45 \mathrm{~kJ} / \mathrm{mol}$ on $\mathrm{Pt} / \mathrm{SZ}$ and $\mathrm{Pt} / \mathrm{ASA}$, respectively.

${ }_{50} \mathrm{E}_{\mathrm{a}(\exp )}$ includes the contribution of the intrinsic activation energy $\left(\mathrm{E}_{\mathrm{a}}\right)$ and the adsorption enthalpies $\left(\Delta \mathrm{H}_{\mathrm{i}}\right)$ of the reactants, according to the Temkin equation (3), where $n_{i}$ are the reaction orders ( $i$ is $\mathrm{T}$ and $\mathrm{H}$ for tetralin and hydrogen, respectively). The intrinsic activation barrier and rate limiting step are likely the 55 same on both catalysts. ${ }^{33}$ The reaction is first order in tetralin, ${ }^{7}$ whereas for hydrogen, the reaction order is positive, around one. 36,37 The adsorption enthalpies of tetralin and hydrogen depend on the electronic state of the Pt particles. However, it is important to note that neither the influence of $\Delta \mathrm{H}_{\mathrm{T}}$ nor that of $\Delta \mathrm{H}_{\mathrm{H}}$ on $\mathrm{E}_{\mathrm{a}(\exp )}$ ${ }_{60}$ can be neglected, because both have similar magnitudes (although the former is larger than the latter). ${ }^{38}$

$\mathrm{E}_{\mathrm{a}(\exp )}=\mathrm{E}_{\mathrm{a}}+\mathrm{n}_{\mathrm{T}} \Delta \mathrm{H}_{\mathrm{T}}+\mathrm{n}_{\mathrm{H}} \Delta \mathrm{H}_{\mathrm{H}}$ 

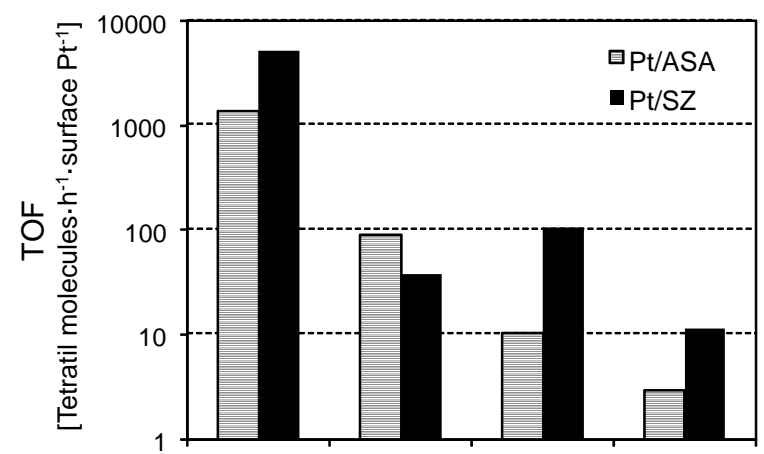

(a) (c)

(d)
Fig. 5 Turnover frequency (TOF) observed in the hydrogenation of tetralin in the absence of heterocompounds (a), in the presence of quinoline (b), dibenzothiophene (c), and quinoline and dibenzothiophene (d). All the activities were measured at $503 \mathrm{~K}$ and 50 bar $\mathrm{H}_{2}$ after $24 \mathrm{~h}$ TOS.

Table 2. Adsorption enthalpies and entropies derived from the gravimetric sorption isotherms of benzene on Pt/ASA and Pt/SZ. The subscripts "sup" and "Pt" denote the parameters corresponding to adsorption on the support and on Pt respectively.

35 a recent report, tetralin and benzothiophene were adsorbed on a series of $\mathrm{Pt}$ catalysts supported on MCM-41 modified with different concentrations of aluminium. ${ }^{42}$ The uptake of both compounds and its interaction strength with the catalyst increased with the addition of $\mathrm{Al}$ and the concomitant increase of support 40 acidity. This observation is explained by increasing cationic character of the supported Pt, which is consistent with our view.

However, as the hydrogenation at the perimeter of Pt particles has an important contribution to the overall process, ${ }^{20,43}$ strong adsorption on Brønsted sites on ASA (due to higher concentration

45 and strength than on SZ) would compensate to some extent the weaker adsorption on the metal surface. Unfortunately, the thermodynamic parameters reported in Table 2 concerning adsorption on the support do not allow us to conclude at this respect because at the temperatures used in the adsorption 50 experiments, the adsorption isotherms include contributions of benzene adsorbed in the whole surface of the supports and not only on acid sites.

The adsorption of $\mathrm{H}_{2}$ on $\mathrm{Pt}$, on the other hand, weakens as the electron deficiency of the metal increases, ${ }^{44}$ and therefore, $\Delta \mathrm{H}_{\mathrm{H}}$

55 has to be less negative with Pt/SZ than with Pt/ASA. Thus, it is reasonable to conclude that the adsorption of tetralin on Brønsted sites and adsorption of hydrogen on electron-deficient Pt lead to

\begin{tabular}{ccccc}
\hline Catalyst & $\begin{array}{c}\Delta \mathrm{H}_{\text {ads, sup. }} \\
\left(\mathrm{kJ} \cdot \mathrm{mol}^{-1}\right)\end{array}$ & $\begin{array}{c}\Delta \mathrm{H}_{\text {ads,Pt. }} \\
\left(\mathrm{kJ} \cdot \mathrm{mol}^{-1}\right)\end{array}$ & $\begin{array}{c}\Delta \mathrm{S}_{\text {ads, sup. }} \\
\left(\mathrm{J} \cdot \mathrm{mol}^{-1} \cdot \mathrm{K}^{-1}\right)\end{array}$ & $\begin{array}{c}\Delta \mathrm{S}_{\text {ads, Pt. }} \\
\left(\mathrm{kJ} \cdot \mathrm{mol}^{-1} \cdot \mathrm{K}^{-1}\right)\end{array}$ \\
\hline $\mathrm{Pt} / \mathrm{SZ}$ & 64 & 73 & 121 & 116 \\
$\mathrm{Pt} / \mathrm{ASA}$ & 47 & 52 & 86 & 65
\end{tabular}

lower $\mathrm{E}_{\mathrm{a}(\exp )}$ on Pt/ASA than on Pt/SZ.

The extent of coke deposition on the catalysts was ${ }_{60}$ explored by comparing the elemental composition and IR spectra of adsorbed $\mathrm{CO}$ on the catalysts before and after

10 Table 3. Elemental analysis of fresh and spent Pt/SZ and Pt/ASA.

reaction. Table 3 shows that the carbon content increases in both

\begin{tabular}{ccccc}
\hline $\begin{array}{c}\text { Support or } \\
\text { catalyst }\end{array}$ & $\begin{array}{c}\text { C content of } \\
\text { fresh sample } \\
\text { (wt.\%) }\end{array}$ & $\begin{array}{c}\text { C content of } \\
\text { spent sample } \\
\text { (wt.\%) }\end{array}$ & $\begin{array}{c}\text { S content of } \\
\text { fresh sample } \\
\text { (wt.\%) }\end{array}$ & $\begin{array}{c}\text { S content of } \\
\text { spent sample } \\
\text { (wt.\%) }\end{array}$ \\
\hline SZ & $<0.1$ & - & 2.14 & - \\
Pt/SZ & $<0.1$ & 2.88 & 1.50 & 1.40 \\
ASA & 0.11 & - & - & - \\
Pt/ASA & 0.12 & 10.50 & - & -
\end{tabular}
catalysts, from traces to 2.88 and $10.5 \mathrm{wt} \%$ in Pt/SZ and $\mathrm{Pt} / \mathrm{ASA}$, respectively. This confirms that deactivation, 65 observed mainly within the first $24 \mathrm{~h}$ TOS, is due to coke deposition. The concentration of sulfur during the reaction is reduced from 1.5 to $1.4 \mathrm{wt}$. \%.

The band of adsorbed $\mathrm{CO}$ in the spectra of the spent catalysts (Figure 3) shifted to lower wavenumbers

${ }^{1}$ Spent catalyst after tetralin hydrogenation $\left(453 \mathrm{~K}, 50\right.$ bar $\mathrm{H}_{2}, 48 \mathrm{~h}$ TOS)

The enthalpies of adsorption for tetralin, dibenzothiophene or quinoline were not accessed in this work. However, the enthalpies of adsorption of benzene on the catalysts provided 15 insight into the interaction of aromatic compounds on metal with varying electronic deficiencies. Table 2 shows the values of adsorption enthalpies and entropies derived from the gravimetric sorption isotherms of benzene on the catalysts. The enthalpy of adsorption of benzene on Pt/SZ was higher than on Pt/ASA (73 20 and $52 \mathrm{~kJ} \cdot \mathrm{mol}^{-1}$, respectively). This is explained by a stronger interaction of the aromatic ring with the $\mathrm{Pt}$ on $\mathrm{SZ}$ that is more electron deficient that the $\mathrm{Pt}$ on ASA. The entropy of of adsorption on Pt was also higher on Pt/SZ than on Pt/ASA (116 and $62 \mathrm{~kJ} \cdot \mathrm{mol}^{-1} \cdot \mathrm{K}^{-1}$, respectively) likely due to the greater 25 entropy losses associated with stronger sorbate-adsorbent interactions. This phenomenon has been referred as the compensation effect. $^{39,40}$

Similarly to the adsorption of benzene on the Pt particles, the enthalpy of adsorption of tetralin has to be higher on Pt/SZ than

30 on Pt/ASA because stronger adsorption of on more electron deficient $\mathrm{Pt}$ particles is expected for all aromatic molecules. Indeed, the covalent character of the interaction between aromatics and d-metals is much larger on a metal with a partially occupied d-band than on one with an fully occupied d-band. ${ }^{41}$ In
70 compared to the fresh catalysts, i.e., from 2068 to $2037 \mathrm{~cm}^{-1}$ for $\mathrm{Pt} / \mathrm{ASA}$ and from 2094 to $2055 \mathrm{~cm}^{-1}$ for $\mathrm{Pt} / \mathrm{SZ}$. This red shift is attributed to the presence of coke, which donates negative charge to $\mathrm{Pt}$ particles increasing the back donation to adsorbed $\mathrm{CO}$ molecules. Coke forms on the metal as inferred from the strong ${ }_{75}$ decrease of the $\mathrm{CO}$ band intensities. Estimating the decrease of the band, $76 \%$ of the metal surface remained available for $\mathrm{CO}$ adsorption for $\mathrm{Pt} / \mathrm{SZ}$, while on Pt/ASA only $21 \%$ of the metal surface was still exposed after the reaction. The dramatic decrease of metal area in Pt/ASA is in line with the significant 80 carbon deposition most likely due to the high acidity of the material.

The hydrogenation activities of both catalysts at $503 \mathrm{~K}$ with a clean feed, in the presence of quinoline, DBT and both compounds are compared in Fig. 5. It is important to mention that 85 taking into account the decrease of exposed metal surface in the spent catalysts (that is, $24 \%$ and $79 \%$ in $\mathrm{Pt} / \mathrm{SZ}$ and Pt/ASA, respectively) the TOF values increase, especially those of Pt/ASA (not shown). However, the trends are preserved and thus the discussion here presented is valid for the catalysts during reaction 90 conditions.

In the absence of heterocompounds, $\mathrm{Pt} / \mathrm{SZ}$ is more active than $\mathrm{Pt} / \mathrm{ASA}$. The most abundant product was cis-decalin, whereas the 
cis- to trans-decalin ratio was nearly the same on both catalysts at the same conversion levels.

The hydrogenation activity of the two catalysts decreased by orders of magnitude with the addition of quinoline or DBT, 5 especially in the presence of both. Pt/ASA is more active than $\mathrm{Pt} / \mathrm{SZ}$ in the presence of quinoline, whereas $\mathrm{Pt} / \mathrm{SZ}$ is the most active in the presence of DBT (in the presence or absence of quinoline). In all cases, the cis- to trans-decalin ratios decreased, compared to that observed in the absence of heterocompounds.

10 This indicated that their presence reduced the strength between tetralin and $\mathrm{Pt}$, either by competitive adsorption or by changing the electronic state. Quinoline was completely converted when present in the feed. The conversion of DBT was 67 and $51 \%$ over $\mathrm{Pt} / \mathrm{SZ}$ and Pt/ASA, respectively, in the absence of quinoline and $1520 \%$ on both catalysts in the presence of quinoline.

Apart from competitive and strong adsorption, $\mathrm{S}$ - and $\mathrm{N}$ containing compounds impose inhibiting effects on specific sites. That is, desulfurization poisons the metal surface via the formation of a sulfide layer, whereas N-containing compounds 20 neutralize the Brønsted sites at the perimeter. Pt/ASA has higher concentration of Brønsted acid sites and, therefore, may keep higher hydrogenation activity in the presence of quinoline than $\mathrm{Pt} / \mathrm{SZ}$ (where neutralization of acid sites would require lower concentration of $\mathrm{N}$-containing compounds). In the presence of ${ }_{25} \mathrm{DBT}$, however, Pt/SZ maintains the highest hydrogenation ability, likely due to relatively low sulfur poisoning originated from weak Pt-S interaction. In turn, this sulfur resistance must be attributed to the higher electron deficiency of Pt on SZ than on ASA (as concluded from XANES and IR of adsorbed CO).

30 The electronegativity and acidity of ASA are higher than that of sulfated zirconia, both properties being correlated with the electron deficiency of supported metal particles. ${ }^{5,8,9}$ Therefore, the much higher electron deficiency on SZ than on ASA is attributed to the interaction of the metal particles with sulfur in 35 the support. ${ }^{13,45,46}$ It is interesting to note that the electronic deficiency of $\mathrm{Pt}$ on sulfated zirconia, i.e., higher than in the reference Pt foil is similar to that observed when $\mathrm{Pt}$ is alloyed with Pd. ${ }^{43,47}$ Therefore, the electron-withdrawing effect of sulfated zirconia is speculated to be similar in magnitude to that 40 imposed by alloying.

The nature of the interaction of the metal particles with the SZ is controversial. Several groups have proposed that $\mathrm{Pt}$ is at least partially sulfided on SZ. ${ }^{48,49}$ There are also indications that the cationic character of $\mathrm{Pt}$ on $\mathrm{SZ}$ is due to $\mathrm{Pt}-\mathrm{O}$ interactions and 45 therefore $\mathrm{Pt}-\mathrm{PtO}_{\mathrm{x}}$ core-shell models have been proposed. ${ }^{45,46} \mathrm{On}$ the other hand, the presence of sulfate groups seems to aid the reduction of oxide Pt species. ${ }^{50}$ Therefore, we are inclined to believe that sulfur partially blocks the metal surface ${ }^{29}$ and that some remaining Pt-O-S bonds, which could also explain the 50 finding of $\mathrm{Pt}-\mathrm{O}$ contributions in literature, ease the electronic withdrawing from $\mathrm{Pt}$ towards the surface sulfate groups. Although more work is needed to differentiate the contributions of these two mechanisms, the occurrence of both lead to strong electron deficiency of Pt on SZ.

\section{${ }_{55}$ Conclusions}

Pt catalysts ( 0.8 wt.\% of Pt), supported on sulfated zirconia (SZ) and amorphous silica alumina (ASA), were synthesized, characterized and tested in hydrogenation of tetralin. The higher textural and acid properties of ASA led to higher Pt dispersion of ${ }_{60} \mathrm{Pt} / \mathrm{ASA}$ than of Pt/SZ. Compared to the respective supports, the acidity remained constant for Pt/ASA. For Pt/SZ, however, the Brønsted acidity decreased, and Lewis acidity increased due to elimination of sulfur during the synthesis. The net outcome was that the concentration and strength of acid sites was higher on ${ }_{65} \mathrm{Pt} / \mathrm{ASA}$ than on $\mathrm{Pt} / \mathrm{SZ}$, which led to stronger deactivation of the former due to coke formation (more than twice in Pt/ASA than in $\mathrm{Pt} / \mathrm{SZ}$ according to elemental analysis and CO-adsorption).

The Pt particles on SZ were more electron deficient than that on ASA or Pt foil according to adsorption of CO followed by IR 70 spectroscopy (on SZ, the bond vibrations of adsorbed CO appear at the highest wavelengths), XANES analysis (the whiteline of the $\mathrm{Pt}$ edge is the most intense for $\mathrm{Pt} / \mathrm{SZ}$ ) and gravimetric sorption of benzene. This electron deficiency in $\mathrm{Pt} / \mathrm{SZ}$ was attributed to the electron-withdrawing effect of sulfate groups on 75 the support.

In the tetralin hydrogenation in absence of poisons $\mathrm{Pt} / \mathrm{SZ}$ was more active than Pt/ASA above $423 \mathrm{~K}$, whereas the latter was more active than the former at $413 \mathrm{~K}$. At $503 \mathrm{~K}$, in the presence of quinoline, Pt/ASA was more active than $\mathrm{Pt} / \mathrm{SZ}$, due to its so higher concentration of Brønsted acid sites, which increased its resistance to neutralization by $\mathrm{N}$-containing compounds. In the presence of dibenzothiophene Pt/SZ retained higher activity than Pt/ASA due to the higher electron deficiency of the former which provided better sulfur resistance. This study shows that inducing 85 electron deficiency in supported Pt particles is crucial to obtain active hydrogenation catalysts, especially in the presence of sulfur-containing compounds. The presence of surface sulfate anions may induce stronger electron deficiency on supported $\mathrm{Pt}$ than the acidity of the support avoiding the drawback of ${ }_{90}$ deactivation due to coke deposition.

\section{Acknowledgements}

The authors thank MEL Cat and Sasol Germany for providing the sulfated zirconia and amorphous silica alumina supports. Parts of this research were carried out at the light source facility DORIS $95 \mathrm{III}$ at DESY, a member of the Helmholtz Association (HGF). The authors are grateful to the HASYLAB staff for their kind assistance during the experiments at the beamline X1.

\section{Notes and references}

\footnotetext{
${ }^{a}$ Lehrstuhl für Technische Chemie 2,Technische Universität München, 100 Lichtenbergstraße 4, D-85747 Garching, Germany.

Fax:+49/89/28913544. E-mail: johannes.lercher@ch.tum.de

${ }^{*}$ These authors contributed equally to this work.

1 A. Stanislaus, B. H. Cooper, Catal. Rev. Sci. Eng., 1994, 36, 75-123.

2 B. H. Cooper, B. B. L. Donnis, Appl. Catal. A., 1996, 137, 203-223.

1053 J. Barbier, E. Lamy-Pitara, P. Marecot, J.P. Boitiaux, J. Cosyns, F. Verna, Adv. Catal., 1990, 37, 279-318.

4 H. Yasuda, T. Sato, Y. Yoshimura, Catal. Today, 1999, 50, 63-71.

5 D. Poondi, M. A. Vannice, J. Catal., 1996, 161, 742-751.

6 J. Wang, L. M. Huang, Q. Li, Appl. Catal. A, 1998, 175, 191-199.

1107 M. F. Williams, B. Fonfé, A. Jentys, C. Breitkopf, J. A. R. van Veen, J. A. Lercher, J. Phys. Chem. C, 2010, 114, 14532-14541.

8 M. F. Williams, B. Fonfé, C. Sievers, A. Abraham, J. A. van Bokhoven, A. Jentys, J. A. R. van Veen, J.A. Lercher, J. Catal., 2007, 251, 485-496.
} 
9 M.F. Williams, B. Fonfé, C. Woltz, A. Jentys, J. A. R. van Veen, J. A. Lercher, J. Catal., 2007, 251, 497-506.

10 G. D. Yadav, J. J. Nair, Micro. Meso. Mat., 1999, 33, 1-48.

11 J. van Gestel, V. T. Nghiem, D. Guillaume, J. P. Gilson, J. C. Duchet, J. Catal., 2002, 212, 173-181.

12 K. Shimizu, T. Sunagawa, C. R. Vera, K. Ukegawa, Appl. Catal. A, 2001, 206, 79-86.

13 T. Tanaka, T. Shishido, H. Hattori, K. Ebitani, S. Yoshida, Physica $B, 1995,208,649-650$.

1014 K. Ebitani, T. Tanaka, H. Hattori, Appl. Catal. A 102 (1993) 79-92.

15 Z. Paál, M. Muhler, R. Schlögl, J. Catal. 143 (1993) 318-321.

16 T. Shishido, T. Tanaka, H. Hattori, J. Catal. 172 (1997) 24-33.

17 S. Maier, A. Jentys, J. A. Lercher, J. Phys. Chem. C, 115 (2011) 8005.

1518 K. V. Klementiev, VIPER and XANDA for Windows, freeware

19 N. Hansen, in Towards a New Evolutionary Computation. Advances on Estimation of Distribution Algorithms (Eds.: J. A. Lozano, P. Larranaga, I. Inza, E. Bengoetxea), Springer, New York, 2006, p. 75.

20 Y. Yu, B. Fonfé, A. Jentys, G. L. Haller, J. A. R van Veen, O. Y.

20 Gutiérrez, J. A. Lercher, J. Catal., 2012, 292, 13-25.

21 M. Choi, Z. Wu, E. Iglesia, J. Am. Chem. Soc., 2010, 132, 91299137.

22 J. H. Kwak, J. Z. Hu, D. H. Mei, C. W. Yi, D. H. Kim, C. H. F. Peden, L. F. Allard, J. Szanyi, Science, 2009, 325, 1670-1673.

2523 A. Clearfield, G.P.D. Serrete, A.H. Khazi-Syed, Catal. Today 20 (1994) 295.

24 F.R. Chen, G. Coudurier, J.F. Joly, J.C. Vedrine, J. Catal. 143 (1993) 616.

25 C. Monterra, G. Cerrato, C. Emanuel, V. Bolis, J. Catal. 142 (1993)

$30 \quad 349$

26 X.B. Li, K. Nagaoka, R. Olindo, J.A. Lercher, J. Catal. 238 (2006) 39

27 J. R. González-Velasco, M. A. Gutiérrez-Ortiz, J. A. GonzálezMarcos, P. Pranda, P. Steltenpohl, J. Catal., 1999, 187, 24-29.

28 D. L. Hoang, S. A. -F. Farrage, J. Radnik, M. -M. Pohl, M.

35 Schneider, H. Lieske, A. Martin, Appl. Catal., A 2007, 333, 67-77.

29 B. Q. Xu, W. M. H Sachtler, J. Catal., 1997, 167, 224-233.

30 A. Dicko, X. Song, A. Adnot, A. Sayari, J. Catal. 150 (1994) 254

31 K. Föttinger, K. Zorn, H. Vinek, Appl. Catal., A 2005, 284, 69-75.

32 A. Jentys, M. Englisch, G. L. Haller, J. A. Lercher, Catal. Lett., 1993, $40 \quad 21,303-308$.

33 P. Chou, A. Vannice, J. Catal., 1987, 107, 140-153.

34 C. M. Grill, M. L. McLaughlin, J. M. Stevenson, R. D. Gonzalez, J. Catal., 1981, 69, 454-464.

35 B. Coq, C. Walter, R. Brown, G. McDougnall, F. Figuéras, Catal.

45 Lett. 39 (1996) 197-203.

36 T. C. Huang, B. C. Kang, Ind. Eng. Chem. Res., 1995, 34, 11401148.

37 T. Fujikawa, K. Idei, K. Ohki, H. Mizuguchi, K. Usui, Appl. Catal. A, 2001, 205, 71-77.

5038 R. C. Santana, S. Jongpatiwut, W. E. Alvarez, D. E. Resasco, Ind. Eng. Chem. Res., 2005, 44, 7928-7934.

39 B. A. De Moor, M. F. Reyniers, O. C. Gobin, J. A. Lercher, G. B. Marin, J. Phys. Chem. C, 2011, 115 1204-1219.

40 F. Eder, M. Stockenhuber, J. A. Lercher, J. Phys. Chem. B, 1997, 101, 5414-5419.

41 W. Liu, J. Carrasco, B. Santra, A. Michaelides, M. Scheffler, A. Tkatchenko, Phys. Rev. B 86 (2012) 245405-1-245405-6.

42 M. Luo, Q. Wang, G. Li, X. Zhang, L. Wang, Catal. Lett. 143 (2013) 454-462.

6043 Y. Yu, B. Fonfé, A. Jentys, G. L. Haller, J. A. R van Veen, O. Y. Gutiérrez, J. A. Lercher, J. Catal., 2012, 292, 1-12.

44 H. Shi, O. Y. Gutiérrez, H. Yang, N. D. Browning, G. L. Haller, J. A. Lercher ACS Catal., 2013, 3, 328-338.

45 K. Ebitani, T. Tanaka, H. Hattori, Appl. Catal. A 102 (1993) 79-92.

6546 T. Shishido, T. Tanaka, H. Hattori, J. Catal. 172 (1997) 24-33.

47 Y. Yu, O. Y. Gutiérrez, G. L. Haller, R. Colby, B. Kabius, A. Jentys, J. A. Lercher, J. Catal., 2013, accepted.

48 Z. Paal, M. Muhler, R. Schogl, J. Catal. 143 (1993) 318-321

49 E. Iglesia, S.L. Soled, G.M. Kramer, J. Catal. 144 (1993) 238-253.

7050 A. Dicko, X. Song, A. Adnot, A. Sayari, J. Catal. 150 (1994) 254261. 